\title{
RAPD-PCR and phylogenetic analysis of $E$. coli isolated from human and cattle urinary tract infections
}

\author{
D.A. Mraidi ${ }^{1}$ and I.J. Lafta ${ }^{2} \odot$ \\ ${ }^{1}$ Veterinary Public Health, Zoonotic Diseases Unit, ${ }^{2}$ Department of Microbiology, College of Veterinary Medicine, \\ University of Baghdad, Baghdad, Iraq
}

\begin{tabular}{l} 
Article information \\
\hline Article history: \\
Received August 10, 2021 \\
Accepted October 29, 2021 \\
Available online December 8, 2021 \\
\hline Keywords: \\
Cattle \\
E. coli \\
RAPD-PCR \\
UTI
\end{tabular}

Correspondence:

I.J. Lafta

inam.j@covm.uobaghdad.edu.iq

\begin{abstract}
This study aimed at isolating uropathogenic Escherichia coli from urinary tract infections (UTIs) of human and cattle to examine the molecular diversity and phylogenetic relationship of the isolates. A total of 100 urine samples were collected from UTIs of human and cattle. The isolates identification was done using routine diagnostic methods and confirmed by Vitek2. Antimicrobial susceptibility was tested against 10 antimicrobials. Random amplified polymorphic DNA (RAPD)-polymerase chain reaction (PCR) was applied to identify the genetic diversity among E. coli isolates from human and animal origin by using five different octamer primers. The gelJ software for the phylogenetic analysis created Dendrograms. Out of 50 human urine samples, E. coli was isolated from $12(24 \%)$ samples, and was positive in 5 out of 50 (10\%) of cattle urine samples. Concerning the antimicrobial susceptibility test, both human and animal isolates revealed rather approximate results when tested mainly against imipenem, cefotaxime, and ciprofloxacin. These antimicrobial data might indicate presence of a degree of similarity between the human and animal isolates. Using RAPD-PCR, three of the primers produced polymorphic bands; therefore, they were used for further analysis of the results. Either of P1, P3 or P4 primers showed presence of similarity between human and cow isolates. To conclude, RAPD-PCR and gelJ software might be of attractive use to identify and analyze the occurrence of genetic relationships, as this could assist in controlling the routes and sources of infection transmission between human and animal in order to prevent zoonotic infections.
\end{abstract}

DOI: 10.33899/ijvs.2021.131100.1918, CAuthors, 2021, College of Veterinary Medicine, University of Mosul.

This is an open access article under the CC BY 4.0 license (http://creativecommons.org/licenses/by/4.0/).

\section{Introduction}

Urinary tract infections (UTIs), among various microbial infections, are of concern due to their economic impacts and health-care problems (1). Infections of the urinary tract are common in most regions of Iraq and remain as a principal health problem in many developing countries (2).

Annually, these infections affect approximately 250 million and cause death of roughly 150 million people worldwide (3). They are significant diseases that might affect different parts of the urinary tract. These infections could appear in different forms varies from symptomatic or asymptomatic, complicated or uncomplicated in the upper or the lower parts of the urinary tract. The form and the severity of infections are directly related to host factors, predisposing factors, and microbial virulence factors (4). Urinary tract infections frequently arise in the lower urinary tract, e.g. urethra and bladder, and if left without proper treatment they can ascend to the upper urinary tract, such as ureters and kidneys, causing severe kidneys damage.

Numerous complications can occur due to UTIs, including: urethra infection (urethritis), bladder infection (cystitis), ureter infection (urethritis), and kidney infection (pyelonephritis) (5). 
In animals, various sources are associated with UTIs, which may happen because of ascending infection from the urachus of neonatal animals. Another pathway for animal infection is via the vulva, which possibly plays an essential role as a site of entry of a number of urinary infections. Furthermore, other factors may predispose for UTIs in cattle, such as bacteremia, septic catheterization, and postcalving disorders. Adding to the factors associated with the natural structure of females, such as short length of urethra, high estrogen levels that may influence the functional integrity of the urethra and urinary bladder epithelium, as well as trauma and urinary tract contamination during parturition (6).

Approximately, $75 \%$ of clinical cases arise in postparturient cows after dystocia, puerperal infection, or abortion, suggesting that infection and inflammation of the lower urogenital tract offer an important predisposing factor (7).

Among microbial infections, Enterobacteriaceae are the most popular causes of UTIs (5). Numerous researchers have isolated different bacterial species from diverse parts of cattle urinary system, including Enterobacteriaceae family members. The causes are most commonly bacteria that constitute part of the microbiota of the gastrointestinal and genital tract (8). The most predominant causative agent causing approximately two-thirds of UTI cases is uropathogenic Escherichia coli (8).

As a molecular typing tool, random amplified polymorphic DNA-based polymerase chain reaction (RAPD-PCR) technique has been used for analyzing the genetic diversity among isolates of human and animal origin. It has an exceptional advantage of molecularly identifying species without prior knowledge of genomic information.

This technique has been used for many reasons including classification and identification of organisms, detection of breeds and analysis of genetic diversity (9).

From what was mentioned above, this study focused on the detection of UTIs caused by E. coli in both human and cattle in order to investigate whether a genetic relationship exists between them. This in turn can help to prevent further occurrence of such infections by controlling the routes and sources of infection transmission between human and animal.

\section{Materials and Methods}

\section{Ethics}

Permission from the hospital authority and signed informed consent from the patients were collected. All human specimens were handled anonymously based on the ethical and legal standards. Concerning cattle, informal approval was obtained from their owners to collect urine samples from the animals who had not been subjected to any previous medication.

\section{Samples collection}

Fifty human urine samples were collected into sterile containers from patients already diagnosed by specialist physicians to have urinary tract infections (UTIs). The patients' ages ranged from 10 to 60 years and from both genders. All of the urine samples were collected from patients who had not taken any medications that interfere with the results. The samples were gathered from Babylon city, Iraq, from private medical laboratories during 2020. Concerning animal urine, 50 urine samples were taken from cattle from both genders and different ages ranged from 1 to 6 years. These animals had suffered from UTIs, as suggested by their owners and as it was clear from their clinical signs, including mucous discharge with little blood and frequent urination. The urine samples were collected from different cattle farms located in Babylon and Karbala provinces, Iraq, during 2020. Briefly, around $10 \mathrm{ml}$ of mid-stream urine was obtained from each suspected animal, and the samples were kept in sterile containers and transported within not more than two hours inside a cool box to the laboratory. Instantly, in the laboratory a small amount of each urine sample was centrifuged, and the sediment was examined under the light microscope to look for presence of bacteria, blood, or any abnormality. The remaining amount of each urine sample (not subjected to centrifugation) was kept in refrigerator to be used later for routine bacteriological diagnosis (10).

\section{Bacterial isolation and identification}

For routine bacteriological diagnosis, firstly, the urine samples were examined in the laboratory by using dipstick and under the microscope to look for the presence of pus and epithelial cells (inflammatory cells) as an indicator of possible infection. Then, a loopful of the urine sample was streaked onto MacConkey's agar and blood agar plates, which were incubated aerobically at $37^{\circ} \mathrm{C}$ for $24-48$ hours (10). Afterwards, the plates were inspected for presence of bacterial growth, and the grown colonies were characterized in terms of their features, hemolysis and reaction on the blood and MacConkey's agars, respectively. The isolates were also identified based on their Gram's reaction. Subsequently, pure Gram-negative colonies were applied for the biochemical tests including: catalase, oxidase, SIM (sulfide indole motility), sugar fermentation on TSI (triple sugar iron), urease production, indole formation, gelatin liquefaction, citrate utilization, methyl red and Voges-Proskauer tests (10). All of the human and animal isolates were confirmed by using the automated Vitek2 system (bio-Merieux SA, France) according to the manufacturer's instructions.

\section{Antimicrobial susceptibility test}

Disk diffusion susceptibility method was performed as described by Performance Standards for Antimicrobial Susceptibility Testing (CLSI) (11). Ten different antimicrobial agents were used involving: Imipenem, Tetracycline, Gentamicin, Chloramphenicol, Amikacin, 
Ciprofloxacin, Vancomycin, Cefotaxime, Ceftazidime, and Erythromycin. Human and animal isolates were tested against each of these antimicrobials. The data were interpreted based on (11).

\section{Genomic DNA extraction}

The bacterial isolates of human and animal were grown into brain heart infusion broth overnight at $37^{\circ} \mathrm{C}$. The next day, the bacterial broth cultures were centrifuged to precipitate all of the bacterial cells. The supernatant was aspirated and discarded, while the cell pellets were kept for DNA extraction.

The Magnesia ${ }^{\circledR} 16$ system (Magnesia, Turkey), an automated extraction system, with Magnesia ${ }^{\circledR}$ genomic bacterial DNA extraction kit (ABIOpure, USA; Cat. No. 501) were used in this study for bacterial DNA isolation. The automated extraction method was used to prevent any kind of contamination from the sample to the worker or vice versa, as well as the cross contamination between the samples or even contaminating the surrounding laboratory environment. In addition, this system guaranteed fully integrated bacterial DNA extraction with highest purity.

This system worked through a ready to use sealed nucleic acid extraction cartridge prefilled with all the necessary reagents and buffers to perform the extraction process. Each buffer and solution in the cartridge was placed in a separated tube in the designed cartridge, and empty tubes were also included to be used during the extraction process to separate and elute the extracted nucleic acid. The system had also a built-in protocol for the bacterial nucleic acid extraction with flexibility in sample source volumes (according to the guidelines of the Magnesia ${ }^{\circledR} 16$ system).

Briefly, the precipitated bacterial cells were resuspended into $400 \mu \mathrm{L}$ of sterilized phosphate buffered saline $(\mathrm{pH}$ 7.4) and placed in a $1.5 \mathrm{~mL}$ Eppendorf tube. Afterwards, $40 \mu \mathrm{L}$ of protease $\mathrm{K}$ enzyme and $10 \mu \mathrm{L}$ of DNA carrier solution were added to the bacterial suspension.

After that, the tubes were placed inside the Magnesia ${ }^{\circledR} 16$-extraction system, and the extraction of genomic DNA from the bacterial samples started. The total run time was $46 \mathrm{~min}$, at the end of the run, a volume of 100 $\mu \mathrm{L}$ of extracted genomic bacterial DNA was eluted, and the samples were stored at $-80^{\circ} \mathrm{C}$ to be used in the PCR experiments (based on Magnesia ${ }^{\circledR}$ genomic bacterial DNA extraction kit).

\section{RAPD markers}

For amplification of DNA segments randomly within the genome of $E$. coli isolates, five different oligonucleotide primers, which are available commercially from eurofins company (RAPD 10mer kits) and supplied by Promega (USA) were used. Table 1 shows the oligonucleotides and their sequences used in this study.
Table 1: The oligonucleotide primers and their sequences

\begin{tabular}{lccc}
\hline No. & Primer & Sequence 5'-3' & GC\% \\
\hline 1 & OPA-17 & GACCGCTTGT & 60 \\
2 & OPN-02 & ACCAGGGGCA & 70 \\
3 & OPU-15 & ACGGGCCAGT & 70 \\
4 & OPW-8 & GACTGCCTCT & 60 \\
5 & OPX-07 & GAGCGAGGCT & 70 \\
\hline
\end{tabular}

\section{RAPD-PCR}

Random amplified polymorphic DNA-based polymerase chain reaction (RAPD-PCR) was used in this study to determine whether a genetic relationship existed between the human and animal isolates of $E$. coli. Initially, for optimizing the conditions for this test, DNA extracted from one sample whose concentration was $25 \mathrm{ng}$ was used in the PCR reaction mixture (12). The PCR mixture consisted of Maxime PCR PreMix kit (iNtRON, Korea), which contained $2 \times$ Master mix solution, dNTP mixture ( $2.5 \mathrm{mM}$, each), $10 \times$ reaction buffer, and i-StarTaq ${ }^{\mathrm{TM}}$ DNA Polymerase $(5 \mathrm{U} / \mu \mathrm{L})$. To this mixture, $\mathrm{P} 1, \mathrm{P} 2, \mathrm{P} 3, \mathrm{P} 4$ or P5 primer was added at a concentration of 20 picomolar. In addition, nuclease free water was added to the mixture up to the final volume of $20 \mu \mathrm{L}$. Using gradient Thermal Cycler (BioRad, USA), the PCR program included: one cycle of initial denaturation at $94^{\circ} \mathrm{C}$ for $3 \mathrm{~min}$, followed by 35 cycles of denaturation at $94^{\circ} \mathrm{C}$ for $1 \mathrm{~min}$, annealing at three temperatures $\left(28,36\right.$, or $\left.40^{\circ} \mathrm{C}\right)$ for $1 \mathrm{~min}$, and extension for $1 \mathrm{~min}$ at $72^{\circ} \mathrm{C}$. Finally, one extension cycle at $72^{\circ} \mathrm{C}$ for 7 min was done (13). Following optimizing the conditions for PCR reaction, RAPD-PCR was performed for two E. coli isolates from human and other two from cattle. Similar PCR program was used as that mentioned above, except that only three primers were used separately, and an annealing temperature of $40^{\circ} \mathrm{C}$ was applied (instructions of BioRad company).

\section{Amplicons analysis}

Gel electrophoresis was done to determine the presence of DNA fragments amplified by the RAPD-PCR reaction. The agarose gel was made by dissolving $1.5 \mathrm{gm}$ of the agarose powder into $100 \mathrm{~mL}$ of TAE buffer $(1 \times)$ using a microwave (14). Then, the melted gel was left to become warm $\left(45-50^{\circ} \mathrm{C}\right)$, poured into its prepared tray, a comb was placed into its suitable place to make holes, and left till the gel solidified at room temperature. After removing the comb and tape from both sides of the tray, it was put inside the electrophoresis tank, which was filled with TAE buffer $(1 \times)$ at a certain level that covers the whole gel. Before loading, $5 \mu \mathrm{L}$ of the PCR products were mixed with $3 \mu \mathrm{L}$ of the loading buffer, and then, the DNA samples were loaded into the gel wells. In addition, $5 \mu \mathrm{L}$ of $1 \mathrm{~Kb}$ DNA ladder (Bioneer, USA) was loaded along with the DNA samples into the gel holes. The electrophoresis process was done horizontally at an electric current of 7 volts $/ \mathrm{cm}$ for $1-2$ 
hours till the tincture reached the other side of the gel, in which the power was switched off. Later, the gel was put in a pool containing $500 \mathrm{~mL}$ of $\mathrm{dH}_{2} \mathrm{O}$ into which $30 \mu \mathrm{L}$ of red safe nucleic acid staining solution was added. Finally, the gel was tested for the DNA bands by exposure to a source of UV with $336 \mathrm{~nm}$ (15).

\section{Phylogenetic analysis}

In silico analysis was done to analyze and compare the results of RAPD-PCR by using GelJ version 2.0 software for MacBook computer. This program is a Java application designed for analyzing DNA fingerprint images. Some of the outstanding features of GelJ are functionality for accurate lane- and band-detection, several methods for computing migration models and generating dendrograms (16).

\section{Results}

\section{Identification of $E$. coli}

Twelve out of $50(24 \%)$ urine samples of human were $E$. coli, but this bacterium was isolated from only 5 out of 50
(10\%) cattle samples, based on the routine bacteriology diagnosis. The identity of the isolates was further confirmed by the Vitek 2 system. In human, approximately $86 \%$ of the patients whose infections were caused by $E$. coli were females. Concerning cattle, roughly $63 \%$ of the UTIs caused by $E$. coli were reported in females.

\section{Antimicrobial susceptibility test}

Concerning human isolates, there were $11,10,9$ and 8 out of $12 \mathrm{E}$. coli isolates resistant to Erythromycin, Vancomycin, Tetracycline, and Ceftazidime, respectively, with a range of resistance from $91.7 \%$ to $66.7 \%$. However, many isolates were susceptible to Cefotaxime (12/12), Chloramphenicol (11/12), Imipenem (10/12), Amikacin (10/12), Ciprofloxacin (9/12), and Gentamicin (8/12) (Table 2). Animal E. coli isolates showed approximately similar pattern of susceptibility and resistance. All of the animal isolates were resistant to each of Erythromycin, Ceftazidime, and Vancomycin. While the resistance to Tetracycline, Gentamicin, and Amikacin was 60\%. Regarding susceptibility, $80 \%$ of the isolates (4 out of 5) were susceptible to Imipenem and Cefotaxime (Table 2).

Table 2: Antimicrobial susceptibility of E. coli isolated from UTIs of human and cattle

\begin{tabular}{lcccccc}
\hline \multirow{2}{*}{ Antimicrobial agent } & \multicolumn{3}{c}{ Human $(\mathrm{N}=12)$} & \multicolumn{3}{c}{ Cattle $(\mathrm{N}=5)$} \\
\cline { 2 - 6 } & $\mathrm{R}(\%)$ & $\mathrm{I}(\%)$ & $\mathrm{S}(\%)$ & $\mathrm{R}(\%)$ & $\mathrm{I}(\%)$ & $\mathrm{S}(\%)$ \\
\hline Imipenem & $1(8.3)$ & $1(8.3)$ & $10(83.3)$ & $1(20)$ & 0 & $4(80)$ \\
Tetracycline & $9(75)$ & 0 & $3(25)$ & $3(60)$ & 0 & $2(40)$ \\
Gentamicin & $2(16.6)$ & $2(16.6)$ & $8(66.6)$ & $3(60)$ & 0 & $2(40)$ \\
Chloramphenicol & 0 & $1(8.3)$ & $11(91.6)$ & $1(20)$ & $1(20)$ & $3(60)$ \\
Amikacin & $2(16.6)$ & 0 & $10(83.3)$ & $3(60)$ & 0 & $2(40)$ \\
Ciprofloxacin & $3(25)$ & 0 & $9(75)$ & $1(20)$ & $1(20)$ & $3(60)$ \\
Vancomycin & $10(83.3)$ & $2(16.6)$ & 0 & $5(100)$ & 0 & 0 \\
Cefotaxime & 0 & 0 & $12(100)$ & 0 & $1(20)$ & $4(80)$ \\
Ceftazidime & $8(66.6)$ & 0 & $4(33.3)$ & $5(100)$ & 0 & 0 \\
Erythromycin & $11(91.9)$ & $1(8.3)$ & 0 & $5(100)$ & 0 & 0 \\
\hline
\end{tabular}

R: Resistant, I: Intermediate, S: Susceptible.

\section{RAPD-PCR optimization}

The optimization trial showed that multiple DNA fragments were amplified by RAPD-PCR. Importantly, P4 was able to amplify more DNA fragments than the other primers at different annealing temperatures. Furthermore, P1 and P3 also amplified several amplicons, especially when annealing temperature of $36^{\circ} \mathrm{C}$ or $40^{\circ} \mathrm{C}$ was used (Figure 1).

However, using $28^{\circ} \mathrm{C}$ was unsuccessful with most of the primers. Therefore, the primers P1, P3 and P4 with an annealing temperature of $40^{\circ} \mathrm{C}$ were used later for RAPDPCR analysis of human and animal isolates.

\section{RAPD-PCR analysis}

The RAPD-PCR technique using three octamer primers (P1, P3 or P4) was differentiate among the E. coli (Figure 2).

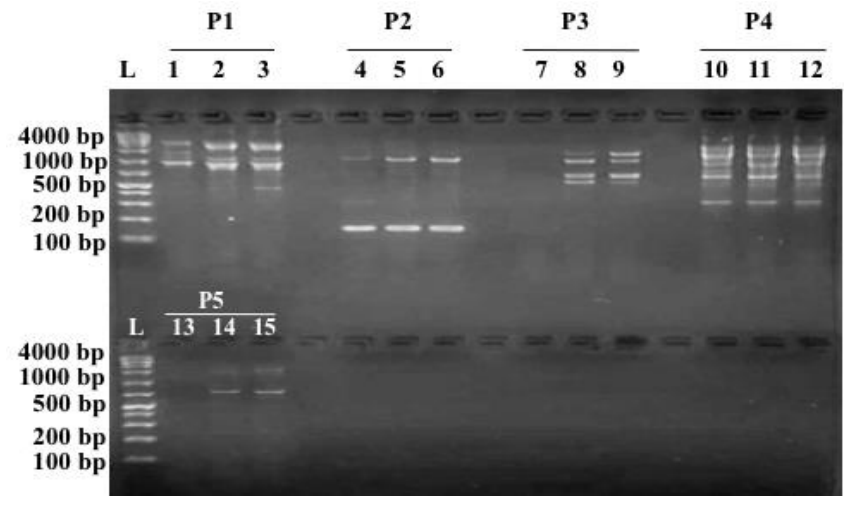

Figure 1: Optimization of RAPD-PCR test conditions using genomic DNA (25 ng) extracted from an E. coli isolate. 


\section{Phylogenetic analysis}

The gelJ software was successful in analyzing the findings of RAPD-PCR. Initial comparison between the human and cattle isolates showed presence of genomic similarity using any of the three primers. While one of the human and another animal isolate (i.e. $\mathrm{H} 2$ and $\mathrm{C} 1$ ).

Showed $100 \%$ identity upon using P3, the other two primers, $\mathrm{P} 1$ and $\mathrm{P} 4$, showed similarity rates of approximately $84 \%$ and $88 \%$, respectively between the human isolate $\mathrm{H} 2$ and the animal isolate $\mathrm{C} 2$ (Figure 3).

\section{Analysis based on P1}

According to Figure 4, there was low rate of similarity of approximately $73 \%$ between the human ( $\mathrm{H} 2)$ and the animal (C2) isolates, based on $\mathrm{P} 1$ primer.

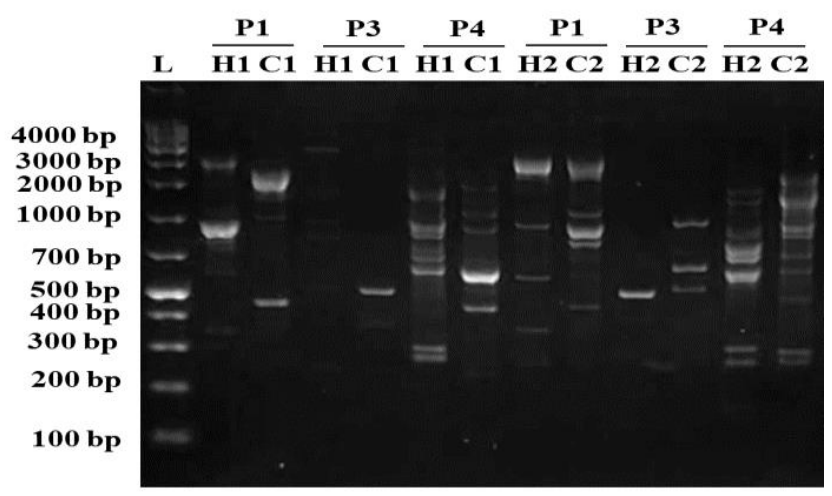

Figure 2: Gel electrophoresis for RAPD-PCR amplified DNA. Three different primers (P1, P3 or P4) were used separately to amplify DNA extracted from $E$. coli of human (isolates H1 and $\mathrm{H} 2$ ) and cattle (isolates $\mathrm{C} 1$ and $\mathrm{C} 2$ ), L: $1 \mathrm{~Kb}$ DNA ladder.

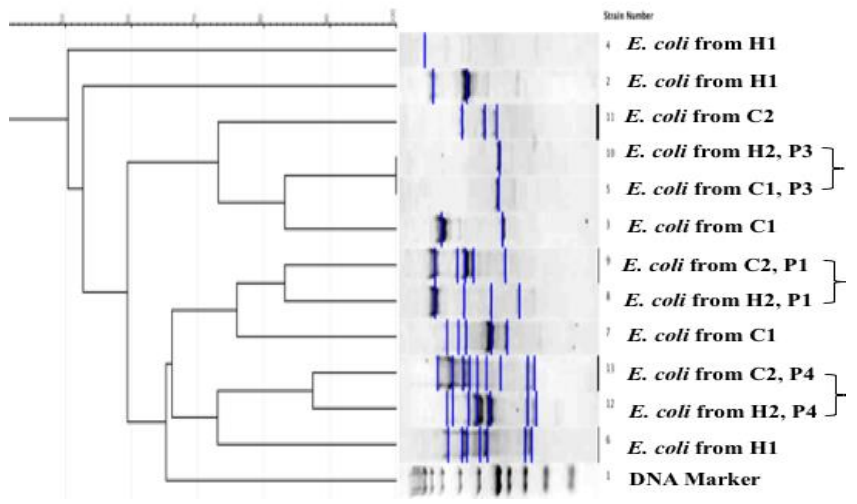

Figure 3: Dendrogram shows genomic analysis of electrophoresed DNA extracted from $E$. coli isolated from human $(\mathrm{H} 1, \mathrm{H} 2)$ and cattle $(\mathrm{C} 1, \mathrm{C} 2)$. The DNA was already amplified by PAPD-PCR using the primers P1, P3 or P4. Only the specifically amplified bands were selected for the genetic analysis.

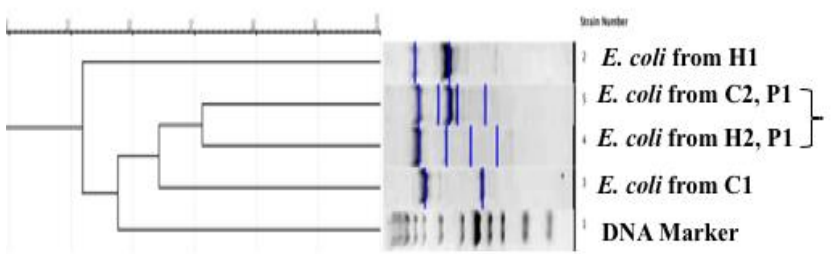

Figure 4: Dendrogram shows genomic analysis of electrophoresed DNA extracted from E. coli obtained from human $(\mathrm{H} 1, \mathrm{H} 2)$ and cattle $(\mathrm{C} 1, \mathrm{C} 2)$. Only specific bands amplified by $\mathrm{P} 1$ primer using RAPD-PCR were selected for the genetic analysis.

\section{Analysis based on P3}

Using P3 primer for RAPD-PCR amplification, there was $100 \%$ identity between a human isolate and another from animal. However, there was neither similarity between the two human isolates nor between the two animal isolates (Figure 5).

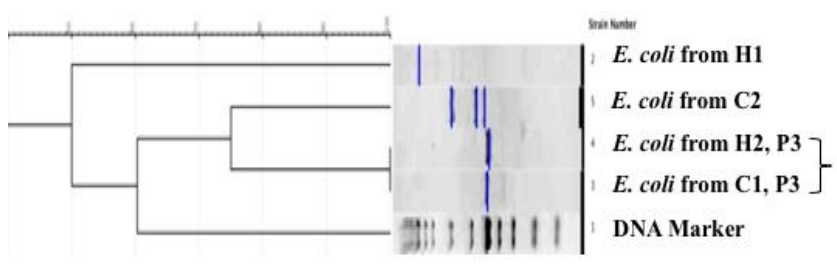

Figure 5: Dendrogram shows genomic analysis of electrophoresed DNA extracted from E. coli obtained from human $(\mathrm{H} 1, \mathrm{H} 2)$ and cattle $(\mathrm{C} 1, \mathrm{C} 2)$ urine. Only specific bands amplified by P3 primer using RAPD-PCR were selected for the genetic analysis.

\section{Analysis based on P4}

Figure 6 shows presence of similarity of roughly $88 \%$ between the human isolate (H1) and the animal isolate (C2). However, there still some similarity (nearly $80 \%$ ) existed between those isolates, mentioned above, and the human isolate $\mathrm{H} 2$.

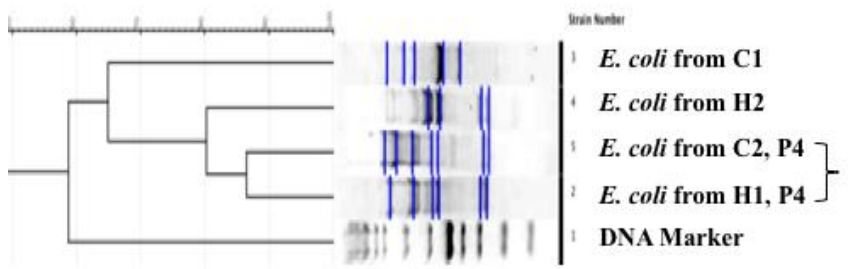

Figure 6: Dendrogram shows genomic analysis of electrophoresed DNA extracted from E. coli obtained from human $(\mathrm{H} 1, \mathrm{H} 2)$ and cattle $(\mathrm{C} 1, \mathrm{C} 2)$ urine. Only specific bands amplified by $\mathrm{P} 4$ primer using RAPD-PCR were selected for the genetic analysis. 


\section{Discussion}

Among various diseases caused by E. coli, urinary tract infections (UTIs) commonly occur. In the current study, the females affected with UTIs outnumbered the males either in human or cattle; this is consistent with other researchers $(17$, 18). In the current study, the most common bacterium isolated from human urine was $E$. coli, which constituted $85.7 \%$ of the enteric bacteria isolated and $26.1 \%$ of all bacterial isolates (19). This result is in agreement with another study in Iraq (18). The same organism was clearly documented to be the major cause of UTI worldwide. Concerning animal isolates, $E$. coli was also the most common isolate $(62.5 \%)$ among the Enterobacteriaceae members (19), but constituted approximately $10.4 \%$ of the total bacteria grown from cattle urine in this study. In comparison with a study performed in a different country, E. coli isolation rate of $45.67 \%$ was reported (20). Then, this study investigated the antimicrobial susceptibility profile of the human and animal UTI isolates. It is very known that the antimicrobial use has increased, and emergence of multi-drug resistant bacteria has become a concern in the community. Many pieces of evidence reveal an increased resistance of the E. coli human and animal isolates to a wide range of antibiotics $(21,22)$.

Moreover, high rates of recurrent UTIs suggest that antibiotics are not effective for all of these infections (5). The findings of the present study show that the vast majority of the human isolates were resistant to many antimicrobials, including: Erythromycin, Vancomycin, Tetracycline, and Ceftazidime. The E. coli animal isolates also showed approximately similar pattern of antimicrobial resistance. Likewise, both human and animal isolates revealed rather approximate antimicrobial sensitivity when tested against each of Imipenem, Cefotaxime, and Ciprofloxacin.

Another purpose of determining the antimicrobial susceptibility profile of the human and animal isolates was a trial to see if any degree of compatibility present between these isolates. Examining the antimicrobial susceptibility data of $E$. coli, isolated in this study, might indicate a degree of similarity between the human and animal isolates. However, the antibiotic susceptibility patterns did not always show enough strain-to-strain variation to discriminate between different isolates (23). Differentiation between isolates with slight variations in resistance profiles requires genetic based methods. Methods of microbial source tracking have been paid more attention, and numerous methods based on genotyping have been designed (24).

Among different techniques, RAPD-PCR is a genotypic identification and characterization system whose profile proves specificity and sensitivity to define bacterial isolates. The RAPD analysis has a great ability to type a wide variety of bacterial species and to detect the genetic differences between isolates (25). It has been used for the molecular typing of multiple bacteria, such as Vibrio, Shigella, Staphylococcus aureus, Salmonella spp, and many others
(26). In comparison with different methods, RAPD-PCR technique was more effective and sensitive for fingerprinting and differentiating $E$. coli strains from human and animal origins (27). Thus, in order to determine whether a genetic correlation exists between the most common human and cattle isolates obtained in the present study, some $E$. coli isolates were selected randomly from human and animal urinary infections to be tested by RAPD-PCR.

Prior to performing the final RAPD-PCR test, an attempt was done for optimizing the PCR conditions using fiveoctamer primers and different annealing temperatures. Although all of the primers were able to amplify genomic DNA fragments, the best primers that showed DNA polymorphism were $\mathrm{P} 1, \mathrm{P} 3$, and $\mathrm{P} 4$, and the best PCR annealing temperature was $40^{\circ} \mathrm{C}$. Therefore, they were tested later to discreminate between the human and animal isolates. Interestingly, each of the three primers was able to differentiate between $E$. coli isolates from human and animal origin using RAPD-PCR. In the current study, the GelJ software was capable of analyzing the phylogenetic relationships. The GelJ software is rather more reliable and easier than other software programs, such as PyElph or NTSYSpc 2.02e (16).

Preliminary comparison between the human and cattle isolates showed presence of genomic similarity using any of the three primers. While one human isolate and another of animal showed $100 \%$ identity when using primer $\mathrm{P} 3$, the other two primers, P1 and P4, showed similarity rates of approximately $84 \%$ and $88 \%$, respectively. Upon doing comprehensive analysis to the RAPD-PCR data using the GelJ software based on analyzing the primers separately, there was rather low rate of similarity of approximately $73 \%$ between the other human and animal isolates, based on P1 primer. Using the P3 primer for RAPD-PCR amplification, there was $100 \%$ identity between one human isolate and another from animal.

Based on the $\mathrm{P} 4$ primer, there was $88 \%$ compatibility between one human and another animal isolate, and a similarity of approximately $80 \%$ was seen between the second human isolate and the same animal isolate. In comparison between these primers, P4 might be the best as it showed more DNA amplicons and was able to discriminate between the isolates more accurately. This finding indicates presence of genetic relationship between human and cow isolates, which in turn, might suppose the same source of UTIs in human and animal.

When comparing the findings of the present study with another performed in Iran, the last found presence of polymorphism of $54.71 \%$ between $E$. coli isolated from UTIs of humans and calves (28), this result is different from that of the current study. 


\section{Conclusions}

To conclude, the RAPD-PCR assay revealed promising findings, especially when used with the GelJ software. They might be of attractive use to control the routes and sources of infection transmission between human and animal in order to prevent zoonotic infections. Furthermore, RAPD is a useful molecular typing method that should be used for epidemiological surveys, diagnosis and identification of virulent strains and isolates responsible for zoonotic infections. Further studies that involve larger numbers of samples are necessary to be discriminated using RAPD-PCR as well as the GelJ software to know the genetic resemblances and discrepancies among different infections of the urinary system.

\section{Acknowledgment}

The authors would like to thank the private medical laboratories in Babylon, and the owners of cattle farms in Babylon and Karbala provinces for their collaboration in providing urine samples.

\section{Conflict of interest}

The authors declare that there are no conflicts of interest regarding the publication of this manuscript.

\section{References}

1. Medina M, Castillo-Pino E. An introduction to the epidemiology and burden of urinary tract infections. Therap Adva Urol. 2019;11:3-7. DOI: $10.1177 \% 2$ F1756287219832172

2. Ibrahim SA, Mohamed DA, Suleman SK. Microbial causes of urinary tract infection and its sensitivity to antibiotics at Heevi pediatric teaching hospital/Duhok City. Med J Babylon. 2020;17(1):109-14. DOI: 10.4103/MJBL.MJBL 6419

3. Azami M, Jaafari Z, Masoumi M, Shohani M, Badfar G, Mahmudi L, Abbasalizadeh S. The etiology and prevalence of urinary tract infection and asymptomatic bacteriuria in pregnant women in Iran:a systematic review and Meta-analysis. BMC Urol. 2019;19(1):43. DOI: 10.1186/s12894-019-0454-8

4. Behzadi P, Behzadi E, Yazdanbod H, Aghapour R, Akbari Cheshmeh M, Omran DS. A survey on urinary tract infections associated with the three most common uropathogenic bacteria. J Clin Med. 2010;5(2):111-115. [available at]

5. Flores-Mireles AL, Walker JN, Caparon M, Hultgren SJ. Urinary tract infections: Epidemiology, mechanisms of infection and treatment options. Nat Rev Microbiol. 2015;13(5):269-284. DOI: $10.1038 \%$ 2Fnrmicro3432

6. John AS, Mboto CI, Agbo B. A review on the prevalence and predisposing factors responsible for urinary tract infection among adults. Euro J Exp Biol. 2016;6(4):7-11. [available at]

7. Esmaeel SA. Bovine pyelonephritis. Infectious and epidemiological diseases. 2019; Part I $-4^{\text {th }}$ year. [available at]

8. Al-Iraqi OM, Shareef AY, Dhahir SH. Urinary tract bacterial infection of local Iraqi buffaloes (Bubalus Bubalis) in Mosul city. Iraqi J Vet Med. 2017;40(2):124-130. DOI: 10.30539/iraqijvm.v40i2.123

9. Reinoso EB, Bettera SG. Random amplified polymorphic DNA PCR in the teaching of molecular epidemiology. Biochem Molecul Biol Educat. 2016;44(4):391-396. [available at]
10. Markey BK, Leonard FC, Achambault M, Cullinana A, Maguire D. Clinical veterinary microbiology. $2^{\text {nd }}$ ed. New York: Mosby Elsevier; 2014.

11. CLSI. Performance Standards for Antimicrobial Susceptibility Testing. 27 $7^{\text {th }}$ ed. CLSI supplement M100. Wayne, PA:Clinical and Laboratory Standards Institute. 2017.

12. Ahmed IM, Al-Sanjary RA, Alkazaly HH. Detection of Mycobacterium paratuberculosis in raw cow's milk using polymerase chain reaction (PCR) technique. Iraqi J Vet Sci. 2020;34(1):83-86. DOI: 10.33899/ijvs.2019.125556.1075

13. Estoepangestie AT, Dewi AR, Suwarno S, Handijatno D, Ernawati R, Tyasningsih W. Molecular analysis of ompA gene Pasteurella multocida Indonesia local isolates. Iraqi J Vet Sci. 2020;35(2):211216. DOI: 10.33899 /ijvs.2019.125934.1191

14. Isihak F. Diagnosis of reovirus infection in broiler breeders flocks by using PCR technique in Erbil province. Iraqi J Vet Sci. 2020;34(1):7781. DOI: 10.33899/ijvs.2019.125469.1007

15. Mraidi DA. Genetic analysis by random amplified polymorphic DNA (RAPD)-Based PCR of Enterobacteriaceae isolated from human and cattle urinary tract infections [master's thesis]. Baghdad: College of Veterinary Medicine, University of Baghdad; 2021.

16. Heras J, Domínguez C, Mata E, and Pascual V. GelJ - a tool for analyzing DNA fingerprint gel images. BMC Bioinformatics 2015;16:270. DOI: 10.1186/s12859-015-0703-0

17. Hadi AM, Sheri FH, Jaccob AA. Urinary tract infection prevalence and antibiotic resistance: A retrospective study in Basra governorate, Iraq. AJPS. 2014;14(2):129-135. [available at]

18. Mahdi BM, Khudhur HB, Abdul-Hussein MM. Bacterial isolates of urine and their susceptibility to antimicrobials. Macedonian $\mathrm{J}$ Med Sci. 2020;8(A):84-88. DOI: 10.3889/oamjms.2020.4086

19. Muridy DA, Lafta IJ. Multidrug resistant enteric bacteria isolated from patients with urinary tract infections. Ann Romanian Soci Cell Biol. 2021;25(6), 2588-2600. [available at]

20. Armanullah M, Anjay, Kumar P, Kumari S, Kaushik P, Archana S, Das Arya K. Prevalence of multi-drug resistant (MDR) Escherichia coli in bovine clinical samples. Int J Curr Microbiol App Sci. 2018;7:1476-1485. [available at]

21. Ahmed1 IM, Al-dabbagh1 SYA, Jwher Dh MT. Molecular characterization of extended spectrum cephalosporin resistant Escherichia coli isolated from dogs. Iraqi J Vet Sci. 2021;35(3):473478. DOI: $10.33899 /$ ijvs.2020.127032.1441

22. Kot B. Antibiotic resistance among uropathogenic Escherichia coli. Polish J Microbiol. 2019;68(4):403-415. 10.33073/pjm-2019-048

23. Ben-Hamouda T, Foulon T, Masmoudi A, Fendri C, Belhadj O, BenMahrez K Molecular epidemiology of an outbreak of multi-resistant Klebsiella pneumoniae in a Tunisian neonatal ward. J Med Microbiol. 2003;52(5):427-433. DOI: 10.1099/jmm.0.04981-0.

24. Tenover F, Arbeit R, Goering R. How to select and interpret molecular strain typing methods for epidemiological studies of bacterial infections: A review for healthcare epidemiologists. Infect Control Hosp Epidemiol. 1997;18:426-439. [available at]

25. Lin CF, Hsu SK, Chen CH, Huang JR, Lo HH. Genotypic detection and molecular epidemiology of extended-spectrum beta-lactamaseproducing Escherichia coli and Klebsiella pneumoniae in a regional hospital in central Taiwan. J Med Microbiol. 2010;59(6):665-671. DOI: $10.1099 / \mathrm{jmm} .0 .015818-0$

26. Toddle MH, Rathore R, Dhama K, Agarwal RK. Epidemiological characterization of Salmonella gallinarum isolates of poultry origin in India, employing two PCR based typing methods of RAPD-PCR and PCR-RFLP. Asian J Anim Vet Adv. 2011;6(11):1037-1051. DOI: 10.3923/ajava.2011.1037.1051

27. Venieri D, Vantarakis A, Komninou G, Papapetropoulou M. Differentiation of faecal Escherichia coli from human and animal sources by random amplified polymorphic DNA-PCR (RAPD-PCR). Water Sci Technol. 2004;50(1):193-198. DOI: $\underline{10.2166 / \text { wst.2004.0053 }}$

28. Afshari A, Rad M, Seifi H A, Ghazvini K. Genetic variation among Escherichia coli isolates from human and calves by using RAPD PCR. Iranian J Vet Med. 2016;10(1):33-40. DOI: 10.22059/ijvm.2016.57048 
فحص الحساسية للبكتريا ضد • ل من المضادات الحيوية. تم استخدام

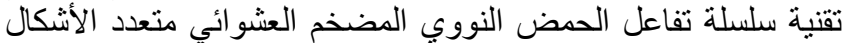

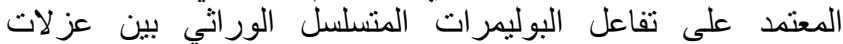

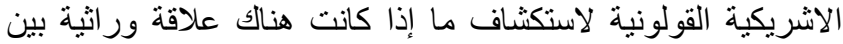

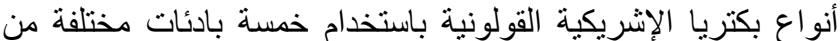

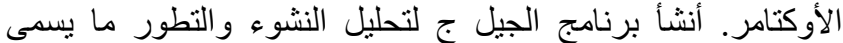

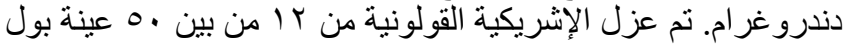

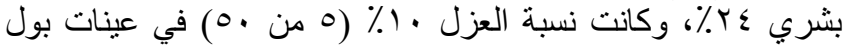

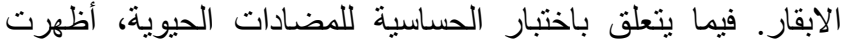

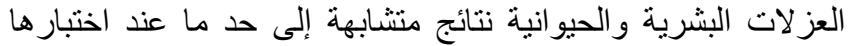

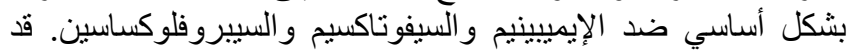

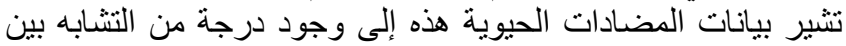

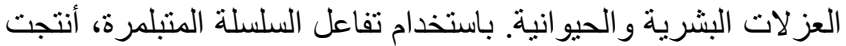

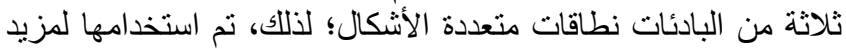

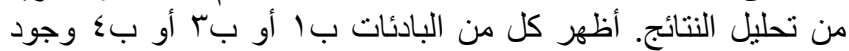

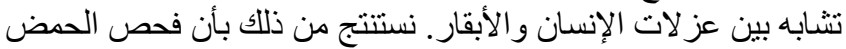

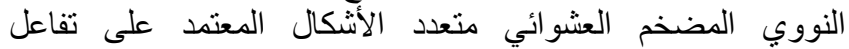
البوليمر ات المتسلسل و الجيل ج ذات فائدة جذابة لتحديد وتحليل التيل حدوث

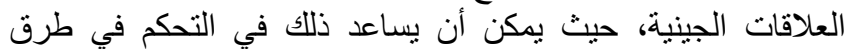

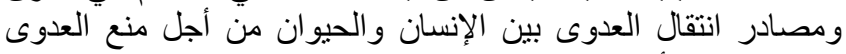

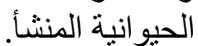

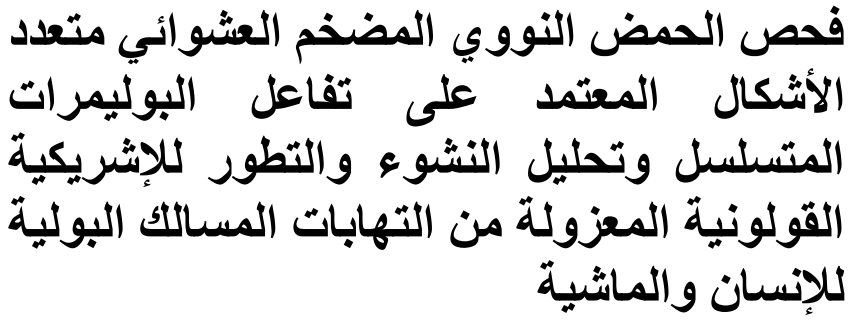

دنيا عبد الواحد مريدي 'و إنعام جاسم لفته‘

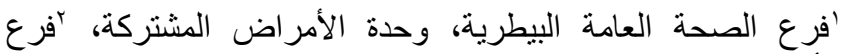
الأحياء المجهرية، كلية الطب البيطري، جامعة بغداد، بغداد، العراق.

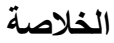

هدفت هذه الدراسة إلى عزل جراثيم الإشريكية القولونبة المسببة

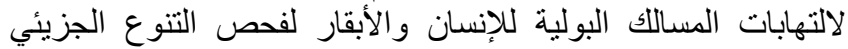

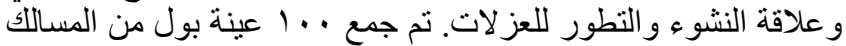

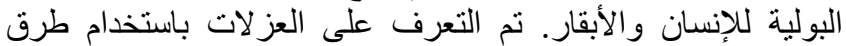

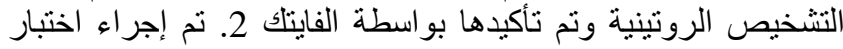

